\title{
"Late for testing, early for antiretroviral therapy, less likely to die": results from a large HIV cohort study in China, 2006-2014
}

\author{
Houlin Tang ${ }^{1}$, Yurong Mao ${ }^{1 *}$, Weiming Tang ${ }^{2,3}$, Jing Han ${ }^{1}$, Juan $\mathrm{Xu}^{1}$ and Jian $\mathrm{Li}^{1}$
}

\begin{abstract}
Background: Timely HIV testing and initiation of antiretroviral therapy are two major determinants of survival for HIV-infected individuals. Our study aimed to explore the trend of late HIV/AIDS diagnoses and to assess the factors associated with these late diagnoses in China between 2006 and 2014.

Methods: We used data from the Chinese Comprehensive Response Information Management System of HIV/AIDS (CRIMS). All individuals who tested positive for HIV between 2006 and 2014 in China and were at least 15 years of age were included. A late diagnosis was defined as an instance in which an individual was diagnosed as having AIDS or WHO stage 3 or 4 HIV/AIDS, or had a CD4 cell count less than 200 cells $/ \mathrm{mm}^{3}$ at the time of diagnosis.

Results: Among the 528,234 individuals ( $\geq 15$ years old) newly diagnosed with HIV between 2006 and 2014, 179,700 (34.0\%) people were considered to have received late diagnoses. The late diagnosis rate decreased from 33.9\% in 2006 to $29.7 \%$ in $2014(P<0.01)$. Late diagnoses were more likely to be found among those who were $45-54$ years old (adjusted odds ratio [aOR]: 3.25, 95\% confidence interval [Cl]: 3.17-3.34) or 55+ years old (OR: $2.94,95 \%$ Cl: $2.86-3.02$ ), male (aOR: 1.15, 95\% Cl: 1.13,1.17), employed as a farmer or rural laborer (aOR: 1.13, 95\% Cl: 1.11-1.14), infected through blood or plasma transfusion (aOR: 4.18, 95\% Cl: 4.02, 4.35), diagnosed at hospitals (OR: 1.17, 95\% Cl: 1.15, 1.19), of Han ethnicity (aOR: 1.30, 95\% Cl: 1.28, 1.32), and married (OR: 1.12, 95\% Cl: 1.11,1.13). Of those people living with HIV (PLHIV) who received late diagnoses, $7.4 \%(8637)$ and $46.1 \%(28,462)$ ultimately died with or without receiving antiretroviral therapy within a year of diagnosis, respectively.

Conclusion: A large proportion of individuals with HIV/AIDS receive late diagnoses, and this proportion has witnessed a slight decline in recent years. Expanded testing is needed to increase early HIV diagnosis and antiretroviral therapy should be recommended to all diagnosed individuals as early as possible to reduce AIDS-related death.
\end{abstract}

Keywords: Late diagnosis, Early mortality, ART, China

\section{Background}

The introduction and expansion of highly active antiretroviral therapy (HAART) has proven to be one of the most remarkable public health measures in reducing the morbidity and mortality caused by the Human Immunodeficiency Virus (HIV) [1-4]. UNAIDS sets an ambitious treatment target to help end the AIDS epidemic: By 2020, $90 \%$ of all people living with HIV know their HIV status, $90 \%$ of people with diagnosed HIV receive

\footnotetext{
* Correspondence: maoyr@chinaaids.cn

${ }^{1}$ National Center for AIDS/STD Control and Prevention, Chinese Center for

Disease Control and Prevention, Beijing, China

Full list of author information is available at the end of the article
}

antiretroviral therapy (ART) and 90\% of all people on HIV treatment achieve viral suppression [5]. However, delayed testing as well as stigma and discrimination against infected individuals places them at risk of receiving delayed antiretroviral therapy [6].

Early detection of HIV infection is a critical factor in controlling the spread of HIV [7]. Timely ART is associated with a better prognosis among HIV-infected individuals and lower rates of disease progression [8]. Prompt linkages with health care systems at the start of ART yields the maximum benefits of HIV medical treatment for people living with HIV (PLHIV) [9] while decreasing the sexual transmission rate of HIV [10-13]. A

(c) The Author(s). 2018 Open Access This article is distributed under the terms of the Creative Commons Attribution 4.0 International License (http://creativecommons.org/licenses/by/4.0/), which permits unrestricted use, distribution, and 
late diagnosis is detrimental to both the individual infected with HIV and the community for two reasons. First, in the absence of timely initiation of ART, the majority of patients will suffer the deleterious effects of HIV infection due to the gradual failure of the immune system, ranging from infection by opportunistic diseases to even death. Second, the propensity for HIV transmission by untested and hence unaware PLHIV is greater $[14,15]$ than for those made aware of their HIV status.

Developed countries such as the USA, Canada, and the European Union have been successful in addressing some of the key operational factors hindering the effective management of diseases affecting PLHIV [16-21]. However, it is estimated that $30 \%$ of PLHIV in the European Union [9] remain undiagnosed, while evidence from the United States suggests that 25\% of the undiagnosed population is responsible for the transmission of new HIV infections in 54\% of cases [7, 22].

The proportion of those who received late diagnoses in industrialized countries is most often reported at between 25 and $45 \%$ of all newly HIV-diagnosed cases [23]. Though the largest proportion of undiagnosed PLHIV resides in developing countries, little research describing their characteristics has been conducted in these settings. In China, HIV voluntary counseling and testing (VCT) is free and can be widely accessed in urban areas. However, this free testing strategy has not been able to prevent a large proportion of cases of late HIV diagnosis for several reasons [24]. Incomplete HIV screening among STD patients in China has been cited as one important cause of missed opportunities for HIV testing [25].

Our study aimed to identify characteristics and trends of cases of late HIV/AIDS diagnosis, and to assess the factors associated with late diagnosis, early mortality, and ART initiation in China between 2006 and 2014.

\section{Methods}

Data sources and definitions

In China, all newly diagnosed HIV/AIDS cases and all recipients of free ART are registered into the Chinese Comprehensive Response Information Management System of HIV/AIDS (CRIMS). CRIMS is managed by the National Centre for AIDS/STD Control and Prevention (NCAIDS) of the Chinese Centre for Disease Control and Prevention (China CDC) and includes the National Case Reporting Database (NCRD) and the National Free Antiretroviral Therapy Database (NFATD). The NCRD collects data on newly diagnosed HIV/AIDS cases, including demographic characteristics, route of infection, site of HIV diagnosis or blood sample source, date of diagnosis, laboratory test results with corresponding test date, and date of death. These cases are followed up every 6 months. During each follow-up, CD4 cell count, counseling and behavior intervention, and other referral services are performed. The NCRD also collects additional data during each follow-up visit, including changes in demographic information, disease stage, CD4 cell count, information on behavioral determinants, and details of ART. The NFATD includes all cases that meet the national treatment criteria and have received free treatment. In China, the national criteria for treatment is a CD4 cell count of less than 350 cells $/ \mathrm{mm}^{3}$ (as of 2009) and later, of less than 500 cells $/ \mathrm{mm}^{3}$ (as of 2014), or being reported as having AIDS, or having WHO stage 3 or 4 HIV/AIDS and having been referred for ART [26-29]. Information on the individual's drug regiment during each follow-up visit is recorded and then uploaded to the CRIMS.

A detailed description of the NCRD and NFATD has been published elsewhere [26], including a discussion of quality control of lab work [28]. There have been several important ART studies based on the data from these two systems in recent years [27-29]. In this study, we updated the results in continuation with earlier findings from the cohort study [27]. We included all newly diagnosed HIV/AIDS cases between 1 January 2006 and 31 December 2014 in mainland China involving individuals aged 15 years and over and excluded individuals who could not be located by local CDCs during follow-up visits.

There were several explanations for the term "late diagnosis" [30-32]. In this study, we classified a case as a "late diagnosis" if an individual was reported as 1) having been diagnosed with AIDS or 2) having been diagnosed with WHO stage 3 or 4 HIV/AIDS, or 3) having an initial CD4 cell count of less than $200 / \mathrm{mm}^{3}$ within one year after the date of HIV diagnosis. Early mortality was defined as death from AIDS-related causes within one year of an HIV/AIDS diagnosis. Cases without a death certificate or without being lost to follow-up as of 31 December 2014, were assumed to be alive. Cases who died of overdose drug use or suicide were excluded.

We defined preventable early mortality as the estimated number of AIDS-related deaths within one year of diagnosis attributed to late diagnosis. The number of preventable early mortality equals to the number of observed AIDS-related deaths within one year of diagnosis minus the estimated number of AIDS-related deaths within one year of diagnosis according to the early mortality rate of those who received timely HIV diagnoses.

\section{Statistical analysis}

We used SAS software (version 9.4; SAS Institute; Cary, NC) for data analysis and MapInfo Professional software (version 15.0; Pitney Bowes; USA) for maps creation. Descriptive analysis was done for late diagnoses across all cases, including gender, age at HIV diagnosis, marital 
status, education level, route of transmission, ethnic group, and screening sites. Screening sites were categorized into three groups: VCT sites, hospitals, and detention centers. Transmission routes were classified into five groups: heterosexual, homosexual, injection drug use, sexual contact and injection drug use, and former paid blood/plasma donation. Odds ratio (OR) was used to assess the factors associated with late diagnosis by means of univariate and multivariate logistic regression models. Variables for which $P$ values were less than 0.05 were considered to be statistically significant.

\section{Results}

A total of 563,961 individuals were newly diagnosed with HIV infection in mainland China during the period between 1 January 2006 and 31 December 2014. A total of 35,727 subjects were excluded from this analysis, as 28,544 cases could not be traced after the initial positive tests and 7183 cases concerned individuals were under 15 years of age (Fig. 1). Among the remaining 528,234 individuals, the majority were male (72.7\%), married (50.2\%), had attained a middle school level education or higher (60.8\%), heterosexual (63.2\%), and belonged to the Han ethnic group (74.6\%). Most were diagnosed a t hospitals $(44.7 \%)$ and VCT sites (28.4\%) (Table 1).

In this cohort, 179,700 (34.0\%) individuals newly diagnosed with HIV infection were classified as "late diagnosis" cases in accordance with the definition. The late diagnosis rate decreased from $33.9 \%$ in 2006 to $29.7 \%$ in $2014(P<0.01)$ (Fig. 2). The proportion of cases of late diagnosis were more than $55 \%$ among four provinces in 2006, three provinces in 2010 and none in 2014 (Fig. 3).

The proportion of cases of late diagnosis was greater among those who were over 45 years old, married, farmers or rural laborers, and of Han ethnicity, infected through heterosexual transmission or former blood/ plasma transfusion, diagnosed at hospitals, (Table 1). In addition, our results indicated that cases of late diagnosis increased with an increase in age in all calendar years during the study period.

As per our results, factors independently associated with an increased likelihood of late diagnosis were being male (aOR: 1.15, 95\% CI: 1.13-1.17), being in an older age group (aOR: 3.25, 95\% CI: 3.17-3.34 for 45-54 years old; aOR: $2.94,95 \%$ CI: $2.86-3.02$ for 55 + years old), having acquired HIV infection through former blood or plasma transfusion (aOR: 4.18, 95\% CI: 4.02-4.35), being of Han ethnicity (aOR: 1.30, 95\% CI: 1.28-1.32), being married or living with a partner (aOR: 1.15, 95\% CI: 1.13-1.17), being farmers (aOR: 1.13, 95\% CI: 1.11-1.14), and being tested at hospitals (aOR: 1.17, 95\% CI: 1.15-1.19).
Around $52.0 \%$ of newly diagnosed cases $(274,552)$ had their CD4 cell count results available within one month of HIV diagnosis (Table 2). This proportion increased from $19.0 \%$ in 2006 to $65.8 \%$ in 2014 . Furthermore, this proportion was the lowest (29.7\%) among those who were infected through injection drug use. Those who were diagnosed at VCT clinics received a timely (within one month) CD4 cell count testing of $60.9 \%$.

Our results indicate that $76.5 \%(404,000)$ of newly HIV diagnosed individuals received testing for CD4 cell count within one year of HIV diagnosis (Table 2). Of these individuals, $32.4 \%(131,095)$ had a CD4 cell count less than 200 cells $/ \mathrm{mm}^{3}$. The proportion with a CD4 cell count test administered within one year increased during the study period from $35.1 \%$ in 2006 to $88.3 \%$ in 2014 , and the proportion of CD4 cell count less than 200 cells $/ \mathrm{mm}^{3}$ decreased from $42.7 \%$ in 2006 to $29.7 \%$ in 2014. Those infected through former blood or plasma transfusion witnessed a high proportion of CD4 cell count less than 200 cells $/ \mathrm{mm}^{3}$. The proportion of CD4 cell count less than 200 cells $/ \mathrm{mm}^{3}$ increased with age, from $13.3 \%$ in $15-24$ age group to $44.8 \%$ in $55+$ age group.

\section{Early mortality and access to ART}

Of the 179,700 individuals who received late diagnoses, excluding 1404 individuals who died of overdose drug use or suicide, the proportions receiving ART within one month of diagnosis and within one year of diagnosis were 30.1 and $65.4 \%$, respectively. The percentage of the individuals who received late diagnoses, received ART, and died within one month of diagnosis was $0.51 \%$. The percentage of the individuals who received late diagnoses, received ART, and died within one year of diagnosis was $7.4 \%$ (Table 3 ). $17.4 \%$ of individuals who received late diagnoses but did not receive ART died within one month of diagnosis, and $46.1 \%$ of those who received late diagnoses without ART died within one year of diagnosis. Upon further analysis, the early mortality was $20.8 \%(37,099 / 178,296)$ among those who received late diagnoses and 9.6\% $(32,626 / 341,072)$ among those with timely diagnoses $(P<0.01)$.

Among PLHIV who received late diagnoses, the proportion experiencing early mortality declined annually from 2006 to 2014 with an increase in the proportion receiving ART (Table 4). The early mortality rates for individuals who received late diagnoses were $29.5 \%$ in 2006 and $14.5 \%$ in 2014 . At the same time, the treatment coverage rates for these individuals within one year of diagnosis were $39.5 \%$ in 2006 and $73.9 \%$ in 2014 . The treatment coverage rate for those who reported having had sex with men was highest $(82.8 \%)(p<0.01)$, therefore, this group also experienced the lowest rate of early mortality (8.0\%) (Table 4). 


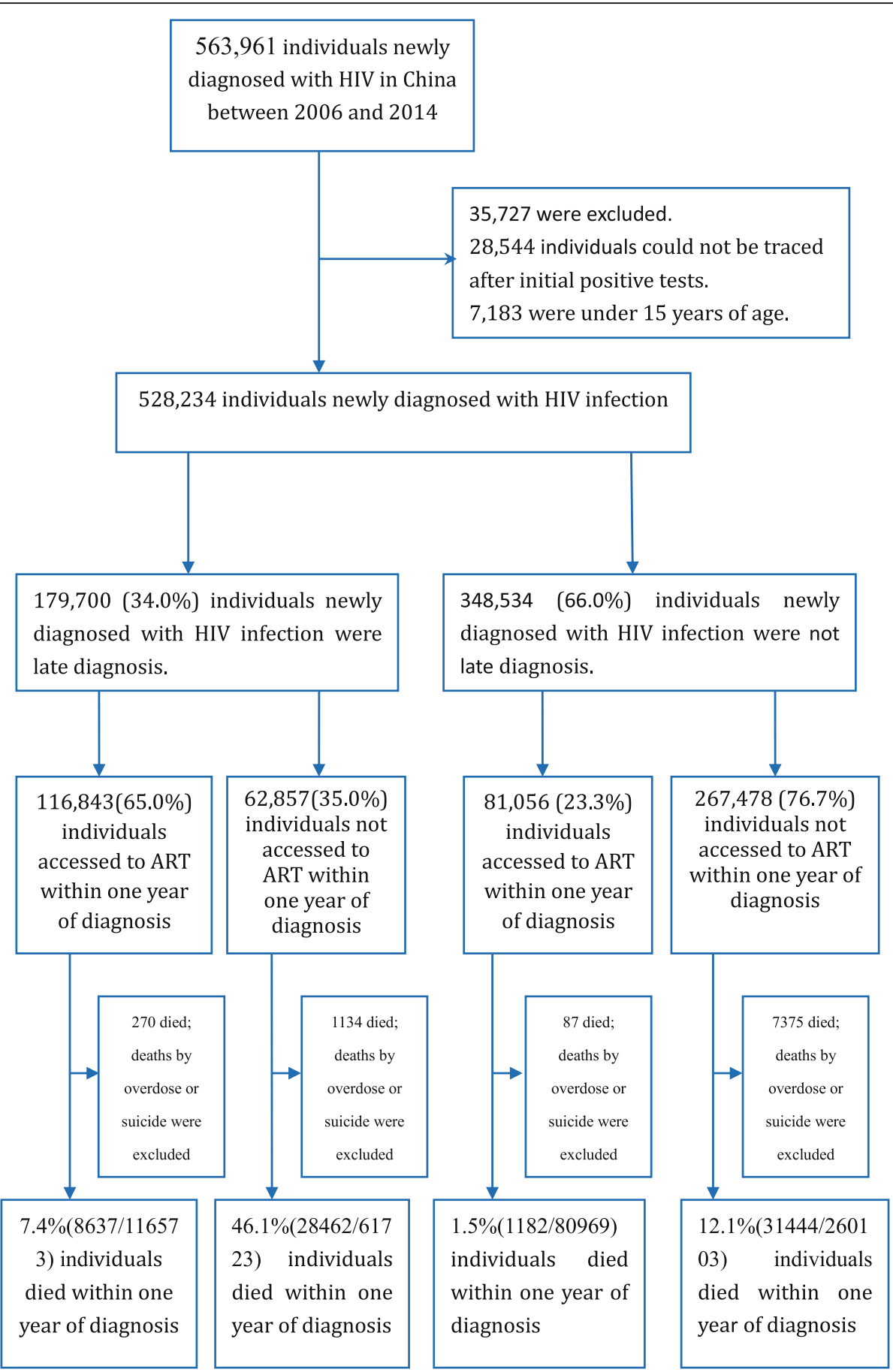

Fig. 1 Study profile

\section{Estimation of preventable early mortality}

Early mortality among those who received timely HIV diagnoses was 9.6\%. Basing our assumptions of previous research [30-32], we presumed in our study that 1) early mortality would be reduced to $9.6 \%$ if there were no late diagnoses; 2) there would be no effect on deaths occurring more than a year after diagnosis; and 3) there would no other competing risks. Based on these conjectures, only 17,116 deaths would have been expected from 2006 to 2014 within a year of diagnosis if the diagnosis was timely. That is, 19,983 deaths would have been avoided during this period, compared to the 37,099 deaths actually observed among the group with late HIV diagnoses. Therefore, 
Table 1 Demographic Characteristics and factors associated with late diagnosis in China between 2006 and $2014(N=528,234)$

\begin{tabular}{|c|c|c|c|c|}
\hline Categories & $\begin{array}{l}\text { Newly diagnosed } \\
\text { (age }>14 \text { years old) }\end{array}$ & $\begin{array}{l}\mathrm{n}(\%) \text { of Late } \\
\text { diagnosis }\end{array}$ & $\begin{array}{l}\text { Unadjusted OR } \\
(95 \% \mathrm{Cl})\end{array}$ & $\begin{array}{l}\text { Adjusted OR } \\
(95 \% \mathrm{Cl})\end{array}$ \\
\hline Total & 528,234 & $179,700(34.0)$ & - & - \\
\hline \multicolumn{5}{|l|}{ Year of HIV diagnosis } \\
\hline 2006 & 26,027 & 8823(33.9) & Ref. & Ref. \\
\hline 2007 & 32,538 & $11,427(35.1)$ & $1.06(1.02-1.09)$ & $1.04(1.00-1.08)$ \\
\hline 2008 & 40,690 & $13,734(33.8)$ & $0.99(0.96-1.03)$ & $0.93(0.89-0.96)$ \\
\hline 2009 & 48,163 & $17,073(35.4)$ & $1.07(1.04-1.11)$ & $0.99(0.95-1.02)$ \\
\hline 2010 & 53,375 & $19,700(36.9)$ & $1.14(1.11-1.18)$ & $0.99(0.96-1.03)$ \\
\hline 2011 & 67,256 & $23,944(35.6)$ & $1.08(1.05-1.11)$ & $0.89(0.86-0.92)$ \\
\hline 2012 & 76,716 & $26,598(34.7)$ & $1.04(1.01-1.07)$ & $0.84(0.81-0.87)$ \\
\hline 2013 & 85,518 & $29,291(34.3)$ & $1.02(0.99-1.05)$ & 0.82(0.79-0.85) \\
\hline 2014 & 97,951 & $29,110(29.7)$ & $0.83(0.80-0.85)$ & $0.65(0.63-0.68)$ \\
\hline \multicolumn{5}{|l|}{ Sex } \\
\hline Female & 144,013 & $49,803(34.6)$ & Ref. & Ref. \\
\hline Male & 384,221 & 129,897(33.8) & $0.97(0.95-0.98)$ & $1.15(1.13-1.17)$ \\
\hline \multicolumn{5}{|l|}{ Age groups(years) } \\
\hline $15-24$ & 74,796 & $12,174(16.3)$ & Ref. & Ref. \\
\hline $25-34$ & 163,089 & $44,161(27.1)$ & $1.91(1.87-1.95)$ & 187(1.82-1.91) \\
\hline $35-44$ & 132,507 & $51,750(39.1)$ & $3.30(3.22-3.37)$ & $2.78(2.72-2.85)$ \\
\hline $45-54$ & 70,158 & $32,262(46.0)$ & $4.38(4.27-4.49)$ & $3.25(3.17-3.34)$ \\
\hline $55+$ & 87,684 & $39,353(44.9)$ & $4.19(4.09-4.29)$ & $2.94(2.86-3.02)$ \\
\hline \multicolumn{5}{|l|}{ Marital status } \\
\hline Single, divorced, or widowed & 256,895 & $74,319(28.9)$ & Ref. & Ref. \\
\hline Married or lives with partner & 264,977 & $104,087(39.3)$ & $1.59(1.57-1.61)$ & $1.12(1.11-1.13)$ \\
\hline \multicolumn{5}{|l|}{ Education } \\
\hline Middle school or more & 331,210 & $111,091(33.5)$ & Ref. & Ref. \\
\hline Primary school or less & 191,811 & $67,212(35.0)$ & $1.07(1.06-1.08)$ & $0.87(0.86-0.89)$ \\
\hline \multicolumn{5}{|l|}{ Occupation } \\
\hline Other & 278,138 & $84,141(30.3)$ & Ref. & Ref. \\
\hline Farmer or rural laborer & 250,096 & $95,559(38.2)$ & $1.43(1.41-1.44)$ & $1.13(1.11-1.14)$ \\
\hline \multicolumn{5}{|l|}{ Ethnic group } \\
\hline Other & 134,406 & $35,356(26.3)$ & Ref. & Ref. \\
\hline Han & 393,828 & $144,344(36.7)$ & $1.62(1.60-1.64)$ & $1.30(1.28-1.32)$ \\
\hline \multicolumn{5}{|l|}{ Route of HIV infection } \\
\hline Heterosexual & 333,753 & $126,658(37.9)$ & Ref. & Ref. \\
\hline Homosexual & 85,252 & $20,891(24.5)$ & $0.53(0.52-0.54)$ & $0.71(0.70-0.73)$ \\
\hline Injection drug use & 73,834 & $14,111(19.1)$ & $0.39(0.38-0.39)$ & $0.63(0.61-0.64)$ \\
\hline $\begin{array}{l}\text { Sexual contact and injection } \\
\text { drug use }\end{array}$ & 5257 & $1147(21.8)$ & $0.46(0.43-0.49)$ & $0.71(0.66-0.76)$ \\
\hline Blood or plasma transfusion & 16,767 & $12,910(77.0)$ & $5.47(5.28-5.68)$ & 4.18(4.02-4.35) \\
\hline \multicolumn{5}{|l|}{ Sites of diagnosis } \\
\hline VCT centers & 150,157 & $54,260(36.1)$ & Ref. & Ref. \\
\hline Hospitals & 236,047 & $97,220(41.2)$ & $1.24(1.22-1.25)$ & $1.17(1.15-1.19)$ \\
\hline Detention centers & 43,231 & $5087(11.8)$ & $0.24(0.23-0.24)$ & $0.35(0.34-0.37)$ \\
\hline others & 98,799 & $23,133(23.4)$ & $0.54(0.53-0.55)$ & $0.59(0.58-0.61)$ \\
\hline
\end{tabular}


Table 1 Demographic Characteristics and factors associated with late diagnosis in China between 2006 and 2014 ( N=528,234) (Continued)

\begin{tabular}{lllll}
\hline Categories & $\begin{array}{l}\text { Newly diagnosed } \\
\text { (age }>14 \text { years old })\end{array}$ & $\begin{array}{l}\mathrm{n}(\%) \text { of Late } \\
\text { diagnosis }\end{array}$ & $\begin{array}{l}\text { Unadjusted OR } \\
(95 \% \mathrm{Cl})\end{array}$ & $\begin{array}{l}\text { Adjusted OR } \\
(95 \% \mathrm{Cl})\end{array}$ \\
\hline Migrant population $^{\mathrm{a}}$ & & & & \\
No & 402,155 & $143,160(35.6)$ & Ref. & Ref. \\
Yes & 126,079 & $36,540(29.0)$ & $0.74(0.73-0.75)$ & $0.94(0.93-0.96)$ \\
\hline
\end{tabular}

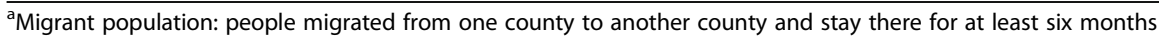

the current burden of early mortality would be reduced by about $53.9 \%$.

\section{Discussion}

It has been thirty years since HIV testing first became available [33]. Despite the decades of availability of testing, it was estimated that at least one-fourth of PLHIV worldwide were unaware of their infection [24, 34-39], and that this ratio could be even higher in China [24]. Our results indicate that promoting timely diagnosis and treatment provided a survival advantage to PLHIV, and that almost $54 \%$ of deaths that occurred within one year of HIV diagnosis could thus be prevented. Our study expanded upon the existing literature [16, 32, 37, 40,41 ] by evaluating late diagnoses among all HIV cases identified between 2006 and 2014 in China, by assessing and mapping the trend of late diagnosis over time and by evaluating factors associated with late diagnosis among HIV cases in China.

In our study, $34.0 \%$ of HIV cases were considered to have received late diagnoses between 2006 and 2014. The late diagnosis rate fluctuated from 2006 to
2014, but slightly decreased from $36.9 \%$ in 2010 to $29.7 \%$ in $2014(P<0.01)$. This declining could be due to the implementation of the provider-initiated HIV testing and counseling (PITC) strategy since 2009. After the initiating of PITC, the HIV testing was significantly scaled up in most of provinces in China [37, 38, 42]. The scaling up of HIV self-testing in China could be another reason for this phenomenon. For example, around $30 \%$ of MSM in China self-reported that they ever self-tested in 2016 [36].

The propensity to receive late HIV testing was greater for older people, those who had acquired HIV infection through former blood or plasma transfusion or heterosexual behaviors, individuals of Han ethnicity, married individuals, and farmers. These results are consistent with the findings of previous studies [31, 43], with the exception of some studies in the U.S. indicated that younger people was more likely to receive late testing $[44,45]$. In recent years, spouses' and regular partners' testing was scaled up in China, because of a series of national and provincial laws, regulations, and policy initiatives.

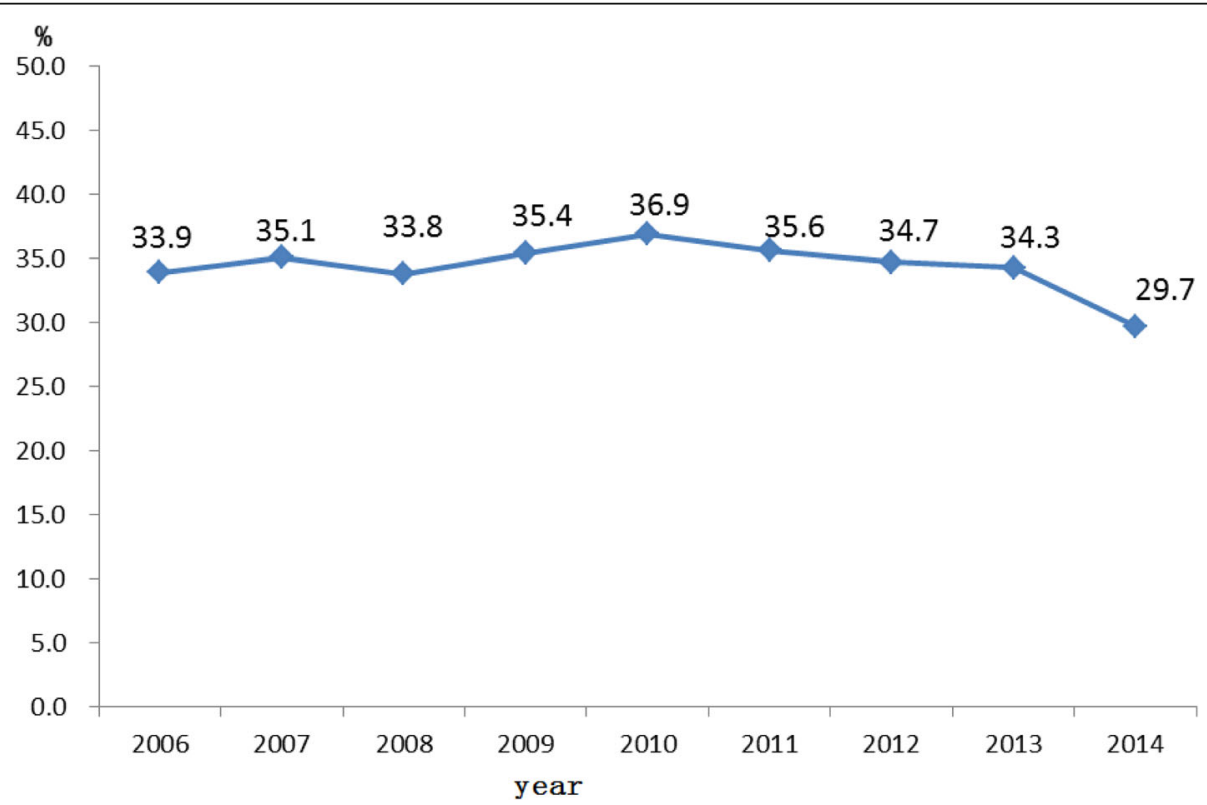

Fig. 2 Proportions of individuals diagnosed late in different calendar years of diagnosis ( $X$ axis: calendar year of diagnosis; $Y$ axis: proportion of late diagnosis) 

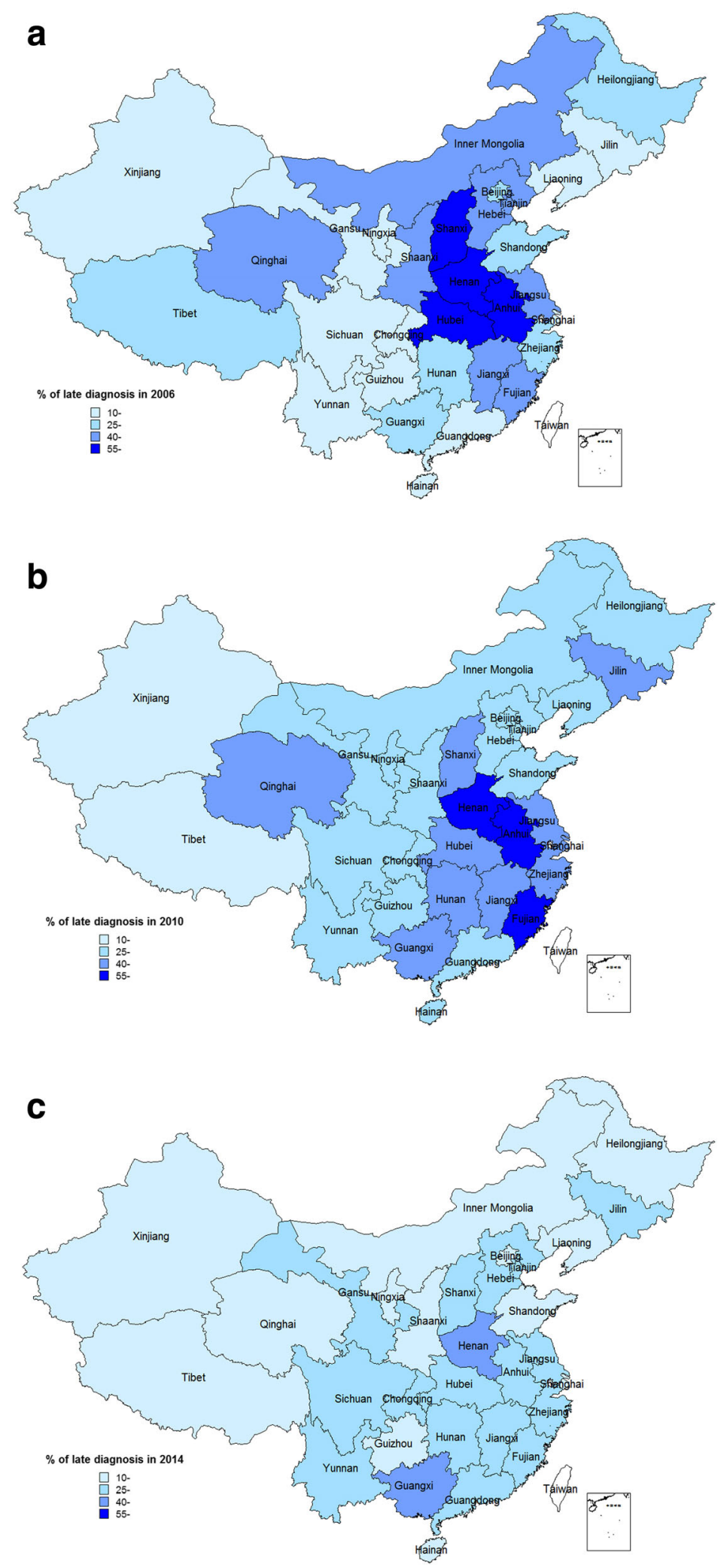

Fig. 3 Proportions of individuals diagnosed late in different calendar years of diagnosis among 31 provinces in China (a: year of 2006, b: year of 2010, c: year of 2014) 
Table 2 Initial CD4 cell counts after diagnosed of HIV newly diagnosed individuals in China between 2006 and $2014(N=528,234)$

\begin{tabular}{|c|c|c|c|c|c|c|c|}
\hline \multirow[t]{2}{*}{ Characteristic } & \multirow[t]{2}{*}{$\begin{array}{l}\text { Newly diagnosed } \\
\text { (age }>14 \text { years old) }\end{array}$} & \multicolumn{2}{|c|}{$\begin{array}{l}\text { Initial CD4 cell count } \\
\text { within one month }\end{array}$} & \multicolumn{2}{|c|}{$\begin{array}{l}\text { Initial CD4 cell count } \\
\text { within one year }\end{array}$} & \multicolumn{2}{|c|}{$\begin{array}{l}\text { Initial CD4 cell counts }<200 \\
\text { cell/ul within one year }\end{array}$} \\
\hline & & $n$ & $\%$ & $n$ & $\%$ & $n$ & $\%$ \\
\hline \multicolumn{8}{|l|}{ Year of HIV diagnosis } \\
\hline 2006 & 26,027 & 4950 & 19.0 & 9129 & 35.1 & 3901 & 42.7 \\
\hline 2007 & 32,538 & 8856 & 27.2 & 15,621 & 48.0 & 6282 & 40.2 \\
\hline 2008 & 40,690 & 14,475 & 35.6 & 23,979 & 58.9 & 8491 & 35.4 \\
\hline 2009 & 48,163 & 20,327 & 42.2 & 32,083 & 66.6 & 11,321 & 35.3 \\
\hline 2010 & 53,375 & 25,110 & 47.0 & 40,073 & 75.1 & 13,511 & 33.7 \\
\hline 2011 & 67,256 & 35,950 & 53.5 & 54,378 & 80.9 & 18,002 & 33.1 \\
\hline 2012 & 76,716 & 45,550 & 59.4 & 66,064 & 86.1 & 20,444 & 30.9 \\
\hline 2013 & 85,518 & 54,931 & 64.2 & 76,191 & 89.1 & 23,474 & 30.8 \\
\hline 2014 & 97,951 & 64,403 & 65.8 & 86,482 & 88.3 & 25,669 & 29.7 \\
\hline \multicolumn{8}{|l|}{ Route of HIV infection } \\
\hline Heterosexual & 333,753 & 183,602 & 55.0 & 264,332 & 79.2 & 96,527 & 36.5 \\
\hline Homosexual & 85,252 & 57,299 & 67.2 & 78,895 & 92.5 & 15,515 & 19.7 \\
\hline Injection drug use & 73,834 & 21,958 & 29.7 & 40,713 & 55.1 & 9168 & 22.5 \\
\hline $\begin{array}{l}\text { Sexual contact and } \\
\text { injection drug use }\end{array}$ & 5257 & 1760 & 33.5 & 3257 & 62.0 & 777 & 23.9 \\
\hline $\begin{array}{l}\text { Blood or plasma } \\
\text { transfusion }\end{array}$ & 16,767 & 7006 & 41.8 & 11,833 & 70.6 & 7142 & 60.4 \\
\hline \multicolumn{8}{|l|}{ Sites of diagnosis } \\
\hline VCT centers & 150,157 & 91,425 & 60.9 & 124,603 & 83.0 & 39,141 & 31.4 \\
\hline Hospitals & 236,047 & 118,702 & 50.3 & 176,834 & 74.9 & 73,114 & 41.3 \\
\hline Detention centers & 43,231 & 12,397 & 28.7 & 23,395 & 54.1 & 3196 & 13.7 \\
\hline others & 98,799 & 52,028 & 52.7 & 79,168 & 80.1 & 15,644 & 19.8 \\
\hline Total & 528,234 & 274,552 & 52.0 & 404,000 & 76.5 & 131,095 & 32.4 \\
\hline
\end{tabular}

The majority of late diagnoses occurred among those who were infected with HIV through heterosexual behaviors. It indicated that there might have been a prolonged period of transmission risk to their sexual partners. Strategies, promoting rapid HIV testing at primary level of health institutions, promoting HIV self-testing, and increasing collaboration with community based organizations (CBOs), should be further implemented. Also, the risk of late diagnosis was significantly higher for those who were infected through former blood or plasma transfusion. Illegal paid plasma donation was prominent in central China in the 1990s and resulted in the infection of the majority of donors with the HIV virus [26, 46, 47]. Most of these PLHIV did not seek testing due to societal discrimination and stigma against HIV. As a result, they were diagnosed with HIV only after they experienced symptoms. Most of these people are located in four provinces in central China, as shown in Fig. 3.

However, the proportion of late testing has decreased among men who have sex with men (MSM) and injection drug users in recent years. This finding may have been due to ongoing intervention programs that promoted testing in these high risk groups $[48,49]$, such as methadone maintenance treatment (MMT) for injection drug users and free HIV testing for MSM provided by $\mathrm{CBOs}$ and VCT clinics. Similar results have been found in other studies [45].

Individuals who present at an advanced stage of immunosuppression are at high risk of clinical events and death and are more likely to have a poor response when they start ART [50, 51]. The proportion of people receiving late diagnoses among newly diagnosed individuals remained at more than 30\% between 2006 and 2013 . However, this proportion has been in decline since 2010. In an era where effective and free testing and free treatment options are available in China, it is alarming that there is a substantial proportion of people were late diagnosed, and they are at higher risk of early death. A records-based retrospective cohort study in China found that the highest mortality rates for AIDS-related death and all-cause death were found in the first year 
Table 3 Early mortality among late diagnosed individuals with or without ART, by month $(N=178,296)$

\begin{tabular}{|c|c|c|c|c|c|c|c|}
\hline \multirow{2}{*}{$\begin{array}{l}\text { Duration of time } \\
\text { from diagnosis }\end{array}$} & \multirow{2}{*}{$\begin{array}{l}\text { Initial CD4 } \\
\text { counts }\end{array}$} & \multicolumn{3}{|l|}{ ON ART } & \multicolumn{3}{|l|}{$\underline{\mathrm{NO} A R T}$} \\
\hline & & $\mathrm{N}$ & No. of death ${ }^{a}$ & $\%$ of death & $\mathrm{N}^{a}$ & No. of death ${ }^{a}$ & $\%$ of death \\
\hline \multirow[t]{8}{*}{ One month } & $0-49$ & 33,897 & 325 & 0.96 & 15,344 & 2449 & 15.96 \\
\hline & $50-99$ & 19,220 & 63 & 0.33 & 7153 & 516 & 7.21 \\
\hline & 100-199 & 37,747 & 44 & 0.12 & 13,934 & 330 & 2.37 \\
\hline & $200-349$ & 17,685 & 14 & 0.08 & 6718 & 81 & 1.21 \\
\hline & $350-499$ & 5135 & 3 & 0.06 & 3301 & 32 & 0.97 \\
\hline & $500-$ & 2041 & 0 & 0.00 & 1977 & 10 & 0.51 \\
\hline & No CD4 test & 848 & 142 & 16.75 & 13,296 & 7316 & 55.02 \\
\hline & subtotal & 116,573 & 591 & 0.51 & 61,723 & 10,734 & 17.39 \\
\hline \multirow[t]{8}{*}{ Three months } & $0-49$ & 33,897 & 1551 & 4.58 & 15,344 & 5705 & 37.18 \\
\hline & $50-99$ & 19,220 & 390 & 2.03 & 7153 & 1399 & 19.56 \\
\hline & 100-199 & 37,747 & 283 & 0.75 & 13,934 & 1000 & 7.18 \\
\hline & $200-349$ & 17,685 & 61 & 0.34 & 6718 & 201 & 2.99 \\
\hline & $350-499$ & 5135 & 15 & 0.29 & 3301 & 77 & 2.33 \\
\hline & $500-$ & 2041 & 3 & 0.15 & 1977 & 34 & 1.72 \\
\hline & No CD4 test & 848 & 398 & 46.93 & 13,296 & 9674 & 72.76 \\
\hline & subtotal & 116,573 & 2701 & 2.32 & 61,723 & 18,090 & 29.31 \\
\hline \multirow[t]{8}{*}{ Six months } & $0-49$ & 33,897 & 2950 & 8.70 & 15,344 & 7963 & 51.90 \\
\hline & $50-99$ & 19,220 & 880 & 4.58 & 7153 & 2253 & 31.50 \\
\hline & 100-199 & 37,747 & 678 & 1.80 & 13,934 & 1684 & 12.09 \\
\hline & $200-349$ & 17,685 & 147 & 0.83 & 6718 & 359 & 5.34 \\
\hline & $350-499$ & 5135 & 39 & 0.76 & 3301 & 157 & 4.76 \\
\hline & $500-$ & 2041 & 14 & 0.69 & 1977 & 70 & 3.54 \\
\hline & No CD4 test & 848 & 560 & 66.04 & 13,296 & 10,838 & 81.51 \\
\hline & subtotal & 116,573 & 5268 & 4.52 & 61,723 & 23,324 & 37.79 \\
\hline \multirow[t]{8}{*}{ Twelve months } & $0-49$ & 33,897 & 4521 & 13.34 & 15,344 & 9796 & 63.84 \\
\hline & $50-99$ & 19,220 & 1520 & 7.91 & 7153 & 3100 & 43.34 \\
\hline & 100-199 & 37,747 & 1385 & 3.67 & 13,934 & 2654 & 19.05 \\
\hline & $200-349$ & 17,685 & 361 & 2.04 & 6718 & 628 & 9.35 \\
\hline & $350-499$ & 5135 & 107 & 2.08 & 3301 & 307 & 9.30 \\
\hline & $500-$ & 2041 & 53 & 2.60 & 1977 & 141 & 7.13 \\
\hline & No CD4 test & 848 & 690 & 81.37 & 13,296 & 11,836 & 89.02 \\
\hline & subtotal & 116,573 & 8637 & 7.41 & 61,723 & 28,462 & 46.11 \\
\hline
\end{tabular}

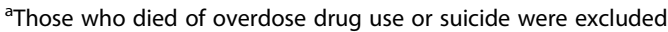

of follow up after HIV diagnosis [52]. This phenomenon could be explained by the fact that about half of the participating cases had already progressed to AIDS before being identified, progression to AIDS was one of the strongest risk factors for AIDS-related death, with an aHR of 7.42 [52].

Individuals who present at an advanced stage of immunosuppression are at high risk of AIDS related diseases and death as well as more likely to have a poorer response to ART [36, 53]. Both HIV testing and ART have been free for PLHIV in China since 2003 [54]. In spite of this policy, our results indicate that as many as $30 \%$ of all newly diagnosed individuals received late diagnoses. Shortening the time from infection to measurement of CD4 cell counts could be an important window for early treatment. We infer that the time from infection to CD4 measurement is a useful indicator for monitoring delays in access to HIV medical care among newly diagnosed PLHIV [55]. In our analysis, $52.0 \%$ of newly diagnosed individuals had their CD4 cell counts available within one month of HIV diagnosis. This proportion increased from $19.0 \%$ in 2006 to $65.8 \%$ in 2014 . 
Table 4 Access to ART and early mortality among late diagnosis individuals within one year of diagnosis between 2006 and 2014 $(\mathrm{N}=178,296)$

\begin{tabular}{|c|c|c|c|c|c|c|}
\hline Characteristics & $\begin{array}{l}\text { Late diagnosis } \\
(\text { age }>14 \text { years old })^{*}\end{array}$ & $\begin{array}{l}\mathrm{N} \text { (\% of access to } \\
\text { ART within one month) }\end{array}$ & $\begin{array}{l}\mathrm{N} \text { (\% of access to } \\
\text { ART within one year) }\end{array}$ & $\begin{array}{l}\mathrm{N} \text { (\% of died after } \\
\text { receiving ART) }\end{array}$ & $x^{2}$ & P-value ${ }^{b}$ \\
\hline Year of HIV diagnosis & & & & & 141.52 & $<0.01$ \\
\hline 2006 & 8675 & 1436(16.6) & $3429(39.5)$ & $267(7.8)$ & & \\
\hline 2007 & 11252 & 2105(18.7) & $5126(45.6)$ & $341(6.7)$ & & \\
\hline 2008 & 13535 & $3051(22.5)$ & $7387(54.6)$ & $568(7.7)$ & & \\
\hline 2009 & 16874 & $3906(23.1)$ & $9527(56.5)$ & $621(6.5)$ & & \\
\hline 2010 & 19532 & $4498(23.0)$ & $12021(61.5)$ & $679(5.6)$ & & \\
\hline 2011 & 23741 & 6383(26.9) & 16355(68.9) & 1076(6.6) & & \\
\hline 2012 & 26445 & $8524(32.2)$ & 19038(72.0) & 1495(7.9) & & \\
\hline 2013 & 29192 & 11068(37.9) & $22212(76.1)$ & 1897(8.5) & & \\
\hline 2014 & 29050 & 12668(43.6) & 21478(73.9) & 1693(7.9) & & \\
\hline Sex & & & & & 137.54 & $<0.01$ \\
\hline Female & 49561 & 15132(30.5) & $32806(66.2)$ & 1959(6.0) & & \\
\hline Male & 128735 & $38507(29.9)$ & $83767(65.1)$ & $6678(8.0)$ & & \\
\hline Age group (years) & & & & & 871.48 & $<0.01$ \\
\hline $15-24$ & 12082 & $3107(25.7)$ & $8305(68.7)$ & $317(3.8)$ & & \\
\hline $25-34$ & 43688 & $12146(27.8)$ & 28734(65.8) & $1436(5.0)$ & & \\
\hline $35-44$ & 51244 & 15499(30.2) & $33684(65.7)$ & $2430(7.2)$ & & \\
\hline $45-54$ & 32084 & 10846(33.8) & $21947(68.4)$ & 1832(8.3) & & \\
\hline $55+$ & 39198 & $12041(30.7)$ & 23903(61.0) & $2622(11.0)$ & & \\
\hline Marital status & & & & & 11.08 & $<0.01$ \\
\hline Single, divorced, or widowed & 73626 & 20957(28.5) & $48061(65.3)$ & $3411(7.1)$ & & \\
\hline Married or lives with partner & 103411 & $32483(31.4)$ & $67970(65.7)$ & $5177(7.6)$ & & \\
\hline Education & & & & & 488.54 & $<0.01$ \\
\hline Middle school or more & 110338 & 34898(31.6) & $77177(69.9)$ & $4792(6.2)$ & & \\
\hline Primary school or less & 66599 & 18585(27.9) & 39012(58.6) & $3826(9.8)$ & & \\
\hline Occupation & & & & & 663.26 & $<0.01$ \\
\hline Other & 83510 & 25305(30.3) & $57787(69.2)$ & $3130(5.4)$ & & \\
\hline Farmer or rural laborer & 94786 & 28334(29.9) & $58786(62.0)$ & $5507(9.4)$ & & \\
\hline Ethnic group & & & & & 16.57 & $<0.01$ \\
\hline Others & 34969 & $9013(25.8)$ & 19866(56.8) & 1335(6.7) & & \\
\hline Han & 143327 & $44626(31.1)$ & $96707(67.5)$ & 7302(7.6) & & \\
\hline Route of HIV infection & & & & & 622.49 & $<0.01$ \\
\hline Heterosexual & 126054 & 40124(31.8) & 83978(66.6) & $6547(7.8)$ & & \\
\hline Homosexual & 20832 & $6951(33.4)$ & $17167(82.4)$ & 646(3.8) & & \\
\hline Injection drug use & 13531 & 1955(14.4) & $5809(42.9)$ & $372(6.4)$ & & \\
\hline Sexual contact and IDU & 1102 & $245(22.2)$ & $560(50.8)$ & $31(5.5)$ & & \\
\hline Blood or plasma transfusion & 12841 & $3722(29.0)$ & $7457(58.1)$ & $917(12.3)$ & & \\
\hline Sites of diagnosis & & & & & 681.88 & $<0.01$ \\
\hline VCT centers & 53825 & 17809(33.1) & $36452(67.7)$ & $2346(6.4)$ & & \\
\hline Hospitals & 96608 & 29659(30.7) & $62791(65.0)$ & 5683(9.1) & & \\
\hline Detention centers & 4859 & 197(4.1) & 1563(32.2) & $62(4.0)$ & & \\
\hline others & 23004 & $5974(26.0)$ & $15767(68.5)$ & $546(3.5)$ & & \\
\hline
\end{tabular}


Table 4 Access to ART and early mortality among late diagnosis individuals within one year of diagnosis between 2006 and 2014 $(\mathrm{N}=178,296)$ (Continued)

\begin{tabular}{|c|c|c|c|c|c|c|}
\hline Characteristics & $\begin{array}{l}\text { Late diagnosis } \\
\text { (age }>14 \text { years old)* }\end{array}$ & $\begin{array}{l}\mathrm{N} \text { (\% of access to } \\
\text { ART within one month) }\end{array}$ & $\begin{array}{l}\mathrm{N} \text { (\% of access to } \\
\text { ART within one year) }\end{array}$ & $\begin{array}{l}\mathrm{N}(\% \text { of died after } \\
\text { receiving ART) }\end{array}$ & $x^{2}$ & P-value ${ }^{b}$ \\
\hline Migrant population $^{a}$ & & & & & 10.03 & $<0.01$ \\
\hline No & 142108 & $43658(30.7)$ & $93717(65.9)$ & $7056(7.5)$ & & \\
\hline Yes & 36188 & $9981(27.6)$ & $22856(63.2)$ & $1581(6.9)$ & & \\
\hline Initial CD4+ cell count & & & & & 10298.66 & $<0.01$ \\
\hline $0-49$ & 49241 & 18191(36.9) & $33897(68.8)$ & $4521(13.3)$ & & \\
\hline $50-99$ & 26373 & $9778(37.1)$ & 19220(72.9) & 1520(7.9) & & \\
\hline $100-199$ & 51681 & 17268(33.4) & $37747(73.0)$ & 1385(3.7) & & \\
\hline $200-349$ & 24403 & $6167(25.3)$ & $17685(72.5)$ & $361(2.0)$ & & \\
\hline $350-499$ & 8436 & $1177(14.0)$ & $5135(60.9)$ & $107(2.1)$ & & \\
\hline $500-$ & 4018 & $476(11.8)$ & $2041(50.8)$ & $53(2.6)$ & & \\
\hline No CD4 records & 14144 & $582(4.1)$ & $848(6.0)$ & $690(81.4)$ & & \\
\hline Total & 178296 & $53639(30.1))$ & $116573(65.4)$ & $8637(7.4)$ & & \\
\hline
\end{tabular}

${ }^{\text {a }}$ Those who died of overdose drug use or suicide were excluded

${ }^{\mathrm{b}}$ The proportion of those who died after ART within one year is compared by different characteristics

It is very important for late diagnosed individuals to receive $\mathrm{CD} 4$ cell count testing immediately, so that they can receive referrals for timely ART and thus reduce their risk of death. In our study, this proportion of cases received ART within one month after the diagnoses increased from $16.6 \%$ in 2006 to $43.6 \%$ in 2014. The average proportion of having CD4 counts within one year was 76\% from 2006 to 2014. The causes of not having CD4 counts testing within one year included death before having CD4 counts, lost to follow up, and inconvenience to access to CD4 count test. To shorten the time to CD4 cell count testing and to improve access to regular testing and treatment, efforts were taken in the past few years to dramatically improve referrals and integration of patient tracking between the health facilities responsible for patients follow up, CD4 cell count testing, and ART delivery [56].

Our analysis suggests that groups at high risk of late diagnosis should be targeted for appropriate public health intervention and encouraged to seek earlier treatment. Scaling up HIV testing is one of the important strategies in implementing this goal. This strategy may bring out a greater proportion of hidden individuals infected with HIV [57]. Another strategy would be to consider population-wide screening for HIV, such as for patients in hospitals. In the U.S., the CDC recommends routine HIV counseling and testing in healthcare settings for patients aged 13-64 years, unless the local HIV prevalence is known to be less than $0.1 \%$ [1].

There are some limitations to consider while interpreting our findings. Firstly, 2.3\% (12,352/528234) individuals were lost to follow-up after HIV diagnoses, and then CD4 cell counts data or having WHO stage 3 or 4 of them were not available at diagnosis. Thus, it is possible that some individuals with AIDS may have been misclassified as having HIV. However, the resulting misclassification will be non-differential and might bias the estimates towards the null, because the proportion of individuals misclassified does not depend on the individual with respect to other variables on the analysis [58]. Secondly, our results couldn't assess differences in mortality in late diagnosed individuals who access to ART based on ART regimen. It needs further research.

\section{Conclusion}

Even with these limitations, our results still indicate that it is important to increase the accessibility of HIV testing services. Routine testing for most individuals has been recommended as a cost-effective strategy and efforts to promote such testing should be developed $[40,53]$.

\section{Abbreviations \\ ART: Antiretroviral Therapy; CBOs: Community Based Organizations; CDC: Centre for Disease Control and Prevention; CRIMS: Chinese Comprehensive Response Information Management System of HIV/AIDS; HAART: Highly active antiretroviral therapy; HIV: Human Immunodeficiency Virus; MMT: Methadone Maintenance Treatment; MSM: Men Who Have Sex with Men; NCAIDS: National Centre for AIDS/STD Control and Prevention: NCRD: National Case Reporting Database; NFATD: National Free Antiretroviral Therapy Database; OR: Odds Ratio; PITC: Provider-Initiated HIV Testing and Counseling; PLHIV: People Living with HIV; VCT: Voluntary Counseling and Testing}

\section{Acknowledgements}

The authors thank all of the health care and laboratory staff at all levels who participated in HIV/AIDS diagnoses, follow-up and data collection for this study. 


\section{Funding}

This study was funded from the National Health and Family Planning Commission of the People's Republic of China (grant\#131-11-0001-0501). The funder had no role in study design, data collection and analysis, decision to publish, or preparation of the manuscript.

\section{Availability of data and materials}

The datasets used and/or analysed during the current study are available from the corresponding author on reasonable request.

\section{Authors' contributions}

$H T, Y M, W T, J H, J X$, and $J$ contributed to the study design and authored the study. HT and YM, conceived and designed the study. HT analyzed the data. $H T, Y M$, and WT wrote the initial draft of this manuscript. HT and YM had full access to all of the data in the study and YM had responsibility for the decision to submit the final manuscript for publication. All authors read and approved the final manuscript.

\section{Ethics approval and consent to participate}

This study was a secondary data analysis using existing Chinese government HIV/AIDS CRIMS data. Therefore, no additional study specific informed consent was necessary for this current study. Patient records and information were de-identified prior to analysis. This study protocol was reviewed and approved by the Institutional Review Board of the National Center for AIDS/ STD Control and Prevention, Chinese Center for Disease Control and Prevention (approval \#X160310409).

\section{Competing interests}

The authors declare that they have no competing interests.

\section{Publisher's Note}

Springer Nature remains neutral with regard to jurisdictional claims in published maps and institutional affiliations.

\section{Author details}

${ }^{1}$ National Center for AIDS/STD Control and Prevention, Chinese Center for Disease Control and Prevention, Beijing, China. ${ }^{2}$ University of North Carolina at Chapel Hill Project-China, Guangzhou, China. ${ }^{3}$ School of Medicine, University of North Carolina at Chapel Hill, Chapel Hill, USA.

\section{Received: 31 October 2017 Accepted: 22 May 2018}

\section{Published online: 13 June 2018}

\section{References}

1. Branson BM, Handsfield HH, Lampe MA, et al. Revised recommendations for HIV testing of adults, adolescents, and pregnant women in health-care settings. MMWR Recomm Rep. 2006;55(RR-14):1-17.

2. Hammer SM, Saag MS, Schechter M, et al. Treatment for adult HIV infection: 2006 recommendations of the international AIDS society-USA panel. Top HIV Med. 2006;3:827-43.

3. Palella FJ Jr, Delaney KM, Moorman AC, et al. Declining morbidity and mortality among patients with advanced human immunodeficiency virus infection. N Engl J Med. 1998;(13):853-60.

4. Detels R, Muñoz A, McFarlane G, et al. Effectiveness of potent antiretroviral therapy on time to AIDS and death in men with known HIV infection duration. Multicenter AIDS Cohort Stud Invest JAMA. 1998;17:1497-503.

5. Sidibé M, Loures L, Samb B. The UNAIDS 90-90-90 target: a clear choice for ending AIDS and for sustainable health and development. J Int AIDS Soc. 2016;(1):211-33.

6. Centers for Disease Control and Prevention. (CDC). Missed opportunities for earlier diagnosis of HIV infection-South Carolina, 1997-2005. MMWR Morb Mortal Wkly Rep. 2006;47:1269-72.

7. Centers for Disease Control and Prevention (CDC). Adoption of protective behaviors among persons with recent HIV infection and diagnosis-Alabama, New Jersey, and Tennessee, 1997-1998. MMWR Morb Mortal Wkly Rep. 2000;23:512-5.

8. Centers for Disease Control and Prevention. (CDC). Late versus early testing of HIV-16 sites, United States, 2000-2003. MMWR Morb Mortal Wkly Rep. 2003;25:581-6.
9. García F, de Lazzari E, Plana M, et al. Long-term CD4+ T-cell response to highly active antiretroviral therapy according to baseline CD4+ T-cell count. J Acquir Immune Defic Syndr. 2004;(2):702-13.

10. McClelland RS, Baeten JM. Reducing HIV-1 transmission through prevention strategies targeting HIV-1-seropositive individuals. J Antimicrob Chemother. 2006:57(2):163-6.

11. Chamot E, Coughlin SS, Farley TA, et al. Gonorrhea incidence and HIV testing and counseling among adolescents and young adults seen at a clinic for sexually transmitted diseases. AIDS. 1999;(8):971-9.

12. George N, Green J, Murphy S. Sexually transmitted disease rates before and after HIV testing. Int J STD AIDS. 1998;(5):291-3.

13. Otten MW Jr, Zaidi AA, Wroten JE, et al. Changes in sexually transmitted disease rates after HIV testing and posttest counseling, Miami, 1988 to 1989. Am J Public Health. 1993;(4):529-33.

14. Delpierre C, Cuzin L, Lert F. Routine testing to reduce late HIV diagnosis in France. BMJ. 2007;(7608):1354-6.

15. Marks G, Crepaz N, Senterfitt JW, et al. Meta-analysis of high-risk sexual behavior in persons aware and unaware they are infected with HIV in the United States: implications for HIV prevention programs. JAIDS. 2005;(4): 446-53.

16. Mukolo A, Villegas R, Aliyu M, et al. Predictors of late presentation for HIV diagnosis: a literature review and suggested way forward. AIDS Behav. 2013;(1):5-30.

17. Yang B, Chan SK, Mohammad N, et al. Late HIV diagnosis in Houston/Harris County, Texas, 2000-2007. AIDS Care. 2010;6:766-74.

18. Brinkhof MW, Dabis F, Myer L, et al. Early loss of HIV-infected patients on potent antiretroviral therapy programmes in lower-income countries. Bull World Health Organ. 2008;7:559-67.

19. Wolbers M, Bucher HC, Furrer H, et al. Delayed diagnosis of HIV infection and late initiation of antiretroviral therapy in the Swiss HIV cohort study. HIV Med. 2008;(6):397-405

20. Krawczyk CS, Funkhouser E, Kilby JM, et al. Factors associated with delayed initiation of HIV medical care among infected persons attending a southern HIV/AIDS clinic. South Med J. 2006;(5):472-81.

21. Bamford LP, Ehrenkranz PD, Eberhart MG, et al. Factors associated with delayed entry into primary HIV medical care after HIV diagnosis. AIDS. 2010; 24(6):928-30.

22. Diez M. Late diagnosis of HIV infection. Revista Espanola de Sanidad Penitenciaria. 2011;2:35-7.

23. Girardi E, Sabin CA, Monforte AA. Late diagnosis of HIV infection: epidemiological features, consequences and strategies to encourage earlier testing. J Acquir Immune Defic Syndr. 2007;46(Suppl 1):S3-8.

24. $\mathrm{MOH}$, UNAIDS, WHO. Update on the HIV/AIDS epidemic and response in China. 2011. Chinese.

25. Tucker JD, Yang L-G, Yang B, et al. Prior HIV testing among STD patients in Guangdong Province, China: opportunities for expanding detection of sexually transmitted HIV infection. Sex Transm Dis. 2012;(3):182-7.

26. Ma Y, Zhang F, Zhao Y, et al. Cohort profile: the Chinese national free antiretroviral treatment cohort. Int J Epidemiol. 2010:4:973-9.

27. Zhang Y, Dou Z, Sun K, et al. Association between missed early visits and mortality among patients of China National Free Antiretroviral Treatment Cohort. J Acquir Immune Defic Syndr. 2012;(1):59-67.

28. Jiang Y, Qiu M, Zhang G, et al. Quality assurance in the HIV/AIDS laboratory network of China. Int J Epidemiol. 2010;39(Suppl 2):ii72-8.

29. Zhang F, Dou Z, Ma Y, et al. Five-year outcomes of the China national free antiretroviral treatment program. Ann Intern Med. 2009;(4):241-51.

30. Grigoryan A, Hall HI, Durant T, et al. Late HIV diagnosis and determinants of progression to AIDS or death after HIV diagnosis among injection drug users, 33 US states, 1996-2004. PLoS One. 2009;2: e4445.

31. Wohl AR, Tejero J, Frye DM. Factors associated with late HIV testing for Latinos diagnosed with AIDS in Los Angeles. AIDS Care. 2009;(9):1203-10.

32. Chadborn TR, Delpech VC, Sabin CA, et al. The late diagnosis and consequent short-term mortality of HIV-infected heterosexuals (England and Wales, 2000-2004). AIDS. 2006;(18):2371-9.

33. Centers for Disease Control and Prevention (CDC). Evolution of HIV/AIDS prevention programs-United States, 1981-2006. MMWR Morb Mortal Wkly Rep. 2006;21:597-603.

34. Bunnell R, Mermin J, De Cock KM. HIV prevention for a threatened continent: implementing positive prevention in Africa. JAMA 2006;(7):855-8. 
35. Levi J. Ensuring timely access to care for people with HIV infection: a public health imperative. Am J Public Health. 2002;(3):339-40.

36. Scognamiglio P, Chiaradia G, Carli GD, et al. The potential impact of routine testing of individuals with HIV indicator diseases in order to prevent late HIV diagnosis. BMC Infect Dis. 2013;13:473.

37. Camoni L, Raimondo M, Regine V, et al. Late presenters among persons with a new HIV diagnosis in Italy, 2010-2011. BMC Public Health. 2013;(1):1-6.

38. Supervie V. Improving prevention and early diagnosis. BMC Infect Dis. 2014; 14(Suppl 2):S6.

39. Ma Y, Dou Z, Guo W, et al. The Human Immunodeficiency Virus Care Continuum in China:1985-2015. Clin Infect Dis. 2018;6:833-9.

40. Harris J, Khatri R. Late diagnosis of HIV in the United Kingdom: an evidence review. 2015. https://core.ac.uk/download/pdf/34724457.pdf. Accessed 12 Oct 2017.

41. Saracino A, Tartaglia A, Trillo G, et al. Late presentation and loss to follow-up of immigrants newly diagnosed with HIV in the HAART era. J Immigr Minor Health. 2014:(4):751-5.

42. Liu Y, Wu Z, Mao Y, et al. Quantitatively monitoring AIDS policy implementation in China. Int J Epidemiol. 2010;39(Suppl 2):ii90-6.

43. Mugavero MJ, Castellano C, Edelman D, et al. Late diagnosis of HIV infection: the role of age and sex. Am J Med. 2007;(4):370-3.

44. Delpierre C, Cuzin L, Lauwers-Cances V, et al. High-risk groups for late diagnosis of HIV infection: a need for rethinking testing policy in the general population. AIDS Patient Care STDs. 2006;(12):838-47.

45. Schwarcz S, Hsu L, Dilley JW, et al. Late diagnosis of HIV infection: trends, prevalence, and characteristics of persons whose HIV diagnosis occurred within 12 months of developing AIDS. J Acquir Immune Defic Syndr. 2006;(4):491-4.

46. Zhang XF, Liu XZ, Tao XR, et al. The epidemiological study on human immunodeficiency virus infection among paid blood donors living in Shandong provincial China comprehensive response project areas. Zhonghua Liu Xing Bing Xue Za Zhi 2005;5:314-316. Chinese.

47. Zhao F, Wang Z, Li WJ. Human immunodeficiency virus type 1 subtypes prevalence in Central China. Yonsei Med J. 2009;(5):644-9.

48. State Council of the People's Republic of China. Further strengthening on AIDS prevention and treatment. 2010. http://www.gov.cn/zwgk/2011-02/16/ content_1804536.htm. Chinese.

49. Ministry of Health of the People's Republic of China. Carry out the program for the prevention and control of HIV/AIDS among men who have sex with men. 2008. http://www.gov.cn/zwgk/2008-03/28/content_931266.htm. Chinese.

50. Opportunistic Infections Project Team of the Collaboration of Observational HIV Epidemiological Research in Europe (COHERE) in EuroCoord, Young J, Psichogiou M, et al. CD4 cell count and the risk of AIDS or death in HIVinfected adults on combination antiretroviral therapy with a suppressed viral load: a longitudinal cohort study from COHERE. PLoS Med. 2012;3: e1001194

51. Guiguet M, Boue F, Cadranel J, et al. Effect of immunodeficiency, HIV viral load, and antiretroviral therapy on the risk of individual malignancies (FHDH-ANRS CO4): a prospective cohort study. Lancet Oncol. 2009;(12):1152-9.

52. Li M, Tang W, Bu K, et al. Mortality among people living with HIV and AIDS in China: implications for enhancing linkage. Sci Rep. 2016;6:28005.

53. Long EF, Brandeau ML, Owens DK. The cost-effectiveness and population outcomes of expanded HIV screening and antiretroviral treatment in the United States. Ann Intern Med. 2010;(12):778-89.

54. Wu Z, Wang Y, Mao Y, et al. The integration of multiple HIV/AIDS projects into a coordinated national programme in China. Bull World Health Organ 2011;(3):227-33.

55. Thanawuth N, Chongsuvivatwong V. Late HIV diagnosis and delay in CD4 count measurement among HIV-infected patients in southern Thailand. AIDS Care. 2008;(1):43-50.

56. Tang H, Mao Y, Shi CX, et al. Baseline CD4 cell counts of newly diagnosed HIV cases in China: 2006-2012. PLoS One. 2014;6:e96098.

57. Wu Z. New challenge and complex situation on HIV/AIDS control and prevention in China. Chin J Public Health. 2011;12:1505-7. Chinese

58. Rothman KJ, Greenland S, Lash TL. Chapter 9. Validity in epidemiologic methods. Lippincott Williams \& Wilkins. 2008:p352-8.

Ready to submit your research? Choose BMC and benefit from:

- fast, convenient online submission

- thorough peer review by experienced researchers in your field

- rapid publication on acceptance

- support for research data, including large and complex data types

- gold Open Access which fosters wider collaboration and increased citations

- maximum visibility for your research: over $100 \mathrm{M}$ website views per year

At BMC, research is always in progress.

Learn more biomedcentral.com/submissions 